\title{
Trends in mortality among California physicians after giving up smoking: 1950-79
}

\begin{abstract}
A study was conducted to assess how lung cancer and other mortality trends among California physicians had been influenced by the high proportion who had given up smoking since 1950. Several sample surveys indicated that the proportion of California physicians who currently smoked cigarettes had declined dramatically from about $53 \%$ in 1950 to about $10 \%$ in 1980 . During the same period the proportion of other American men who smoked cigarettes had declined only modestly, from about $53 \%$ to $38 \%$. Using the 1950 American Medical Directory a cohort of 10130 California male physicians was established and followed up for mortality till the end of 1979, during which time 5090 died. The information from follow up and death certification was exceptionally good. The standardised mortality ratio for lung cancer among California male physicians relative to American white men declined from 62 in 1950-9 to 30 in 1970-9. The corresponding decline in standardised mortality ratio was from 100 to 63 for other smoking related cancer, from 106 to 71 for ischaemic heart disease, and from 62 to 35 for bronchitis, emphysema, and asthma. The standardised mortality ratio remained relatively constant for other causes of death not strongly related to smoking. The overall ratio declined in all age groups at a rate of about $1 \%$ a year. The total death rate among all physicians converged towards the rate among non-smoking physicians. By the end of the study period physicians had a cancer rate and total death rate similar to or less than those among typical United States nonsmokers.

This "natural experiment" shows that lung cancer became relatively less common on substantial elimination of the primary causal factor, cigarette smoking. Other smoking related diseases also became relatively less common, though factors other than cigarette smoking may have contributed to this change.
\end{abstract}

\section{Introduction}

Based on vast amounts of epidemiological, clinical, and experimental evidence, ${ }^{14}$ it is generally accepted that cigarette smoking is causally related to many diseases, particularly lung cancer. What happens in actual practice when an entire population with a large proportion of smokers stops smoking, however, remains to be determined. Epidemiological data on groups of self selected former smokers indicate that over about 15 years their total death rate declines from that of current smokers to about that of people who have never smoked and their death rate from lung cancer to about twice that of people who have never smoked.

Some investigators, however, have questioned the causal association between smoking and mortality. ${ }^{56}$ Indeed, three recent randomised controlled trials failed to show a statistically

School of Public Fealth and Jonsson Comprehensive Cancer Center, University of California, Los Angeles, CA 90024

JAMES E ENSTROM, PHD, associate research professor

significant reduction in total mortality that was directly attributable to stopping smoking. ${ }^{7-9}$ These trials primarily focused on cardiovascular disease, however, and were not large enough to assess lung cancer. Concern about this issue is still relevant because despite a steady gradual decline in cigarette smoking by American men and over a $60 \%$ decline per caput in tar and nicotine intake, the overall death rate from lung cancer in men has continued to increase. ${ }^{3}$ Only in age groups below 50 years, where very few deaths occur, has the lung cancer rate levelled off or declined slightly. ${ }^{3}$

Almost all United States male physicians have stopped smoking, ${ }^{2}$ and thus it is of interest to determine if this larger reduction in cigarette smoking has affected their death rate from lung cancer and other causes relative to the death rates in the general male population. This represents a natural experiment which tests whether the disease in the population as a whole diminishes when the causal agent is removed. In the only other study of this type British physicians compared with the general British male population showed a relative decline in deaths from lung cancer at all ages and in total deaths under the age of 65 corresponding to a relative decline in their cigarette smoking from 1951 to $1971 .{ }^{410}$

\section{Methods}

All California male physicians listed in the 1950 American Medical Directory (18th edition) who were alive on 1 January 1950 and members of the American Medical Association ${ }^{11}$ were studied prospectively over 30 years. Though I intend to analyse data on all California physicians, I have limited this initial report to members of the AMA because they are relatively easier to follow up and to men because they make up almost the entire sample. Table I summarises the initial selection of the physicians and their subsequent classification by follow up status.

TABLE I-Physicians studied and follow up status

All California physicians reportedly in 1950 American Medical Directory (18th ed)

All California physicians actually coded from 1950 American Medical Directory

California AMA member

California male AMA members

列 25 years

nuary 1950

nown deaths from 1 January 1950 to 31 December 1979

California death certificate information

f $A M A$ obituary with cause of death

IAMA obituary without cause of death

Alive on 31 December 1979
Lost to follow up (disappeared from American Medical Directory

and no confirmation of death located)

No

16673

16656

10805

10186

10130

4951

89

Of the 16673 California physicians reportedly in the 1950 directory, 16656 were actually computer coded for follow up. Of these, 10805 were members of the AMA; 10186 were male members and 10130 male members alive and at least 25 years of age on 1 January 1950. The directory gives full name, year of birth, medical school, specialty, AMA membership, and city and state of residence. Sex was determined from death certificates of those who died, from first and middle names for most of those still alive, and from Department of Motor Vehicle records for those still alive but whose first and middle names were not specific for sex.

Passive mortality follow up was conducted by using several standard sources, including obituary notices in $\mathcal{F} A M A$ and California Medicine (called the Western Fournal of Medicine since 1974) for about $85 \%$ of all known deaths; an AMA computer tape containing essentially all 
deaths among California physicians during 1969-79; and California Department of Health Services microfiche and computer tapes containing death certificate information on all deaths among California residents since 1960 and alphabetical index books for all deaths among California residents during 1949-59. Those physicians listed in the 1979 American Medical Directory (27th edition) and not known to be dead from any of the above sources were assumed to be alive on 31 December 1979. This assumption was confirmed in a random sample of physicians from current California Department of Motor Vehicle records and from telephone directories since 1979. A physician not listed in the 1979 American Medical Directory and not known to be dead was regarded as lost to follow up from the midpoint between the last edition in which he was listed and the next edition.

Death certificates were obtained for essentially all deaths among California physicians during 1950-9, and computer tape records summarising the death certificates were obtained for essentially all deaths among California physicians during 1960-79. For nonCalifornia deaths (about $4 \%$ of the total) the date, place, and cause given in the $\mathcal{F} A M A$ obituaries were used. Follow up to 31 December 1979 was at least $99 \%$ complete in terms of identifying a date and place of death for those who had died and a 1979 address for those still alive. Cause of death information was obtained for $98 \%$ of all known deaths. Less than $1 \%$ of the physicians were lost to follow up. The underlying cause of death for each California death certificate was determined by the state nosologist using the appropriate revision of the International Classification of Diseases and was assumed to be correct. Only six death certificates gave an ill defined cause. Cohort life table analysis was done by using a programme developed by Monson to calculate ratios of observed to expected deaths for selected causes based on comparison with contemporaneous US white men.12

Direct questionnaire data were not collected on this cohort of California physicians in 1950, but their approximate cigarette smoking habits over time were ascertained from several existing cross sectional surveys such as a December 1966 sample of 2948 California physicians $^{13}$ (unpublished data of the California Medical Association's Bureau of Research and Planning, September 1967), 1965 and 1974 samples of 55 Alameda County physicians and lawyers ${ }^{14}$ (L Breslow and J E Enstrom, unpublished data), a 1971 sample of 375 San Francisco Bay area physicians, ${ }^{15}$ and a 1980 sample of 500 Los Angeles County physicians. ${ }^{16}$ The 1966 sample contained data on how many years previously the former smokers had stopped, permitting an approximation of the smoking prevalence back to 1950 by appropriately combining the former and current smokers from 1966. Data were also available on how many cigarettes a day the physicians consumed. ${ }^{13} 14$

Data on the prevalence of smoking among California physicians were consistent with numerous other surveys conducted since 1950 in other states, primarily Massachusetts, Rhode Island, New York, and Florida, as well as national samples in 1959, 1964, 1967, 1970, and 1975, which included California. ${ }^{217-20}$ Most of these surveys were potentially subject to bias by non-response, but the bias was not likely to be important given the high degree of consistency among the many different surveys and the very large changes over time. One investigation showed that the true percentage of smoking physicians was 1.15 times the percentage reported based on a $70^{\circ}$, response to a mailed questionnaire. ${ }^{21}$ Most of the non-California studies have already been summarised elsewhere, ${ }^{2}$ but several additional ones are included here. ${ }^{17-20}$ Similar data on all American men are available based on representative national samples conducted periodically since $1955 .^{23}$

\section{Results}

The rationale of this analysis is that if giving up smoking reduces the risk of death then the mortality rates of physicians relative to those of other men should decrease if the physicians stop smoking to a greater extent. This would happen only if smoking were important enough as a cause of disease for changes in smoking habits to outweigh the effects of possible changes in other factors in life style, efficacy of treatment, accuracy of death certification, and the effect of reduced cigarette consumption showed itself in 20 years or so. The most likely cause of death to be affected is lung cancer, because it has a strong dose response relation with smoking and has no other risk factors comparable to smoking.

This study avoids the bias potentially inherent in studies based on self selected questionnaire respondents, as in the British study. ${ }^{10}$ This study includes all California physicians with only the two restrictions that they were men and members of the AMA in 1950. The second restriction was added only to facilitate a prompt and complete follow up. We plan eventually to study all California physicians, and preliminary results on follow up of a sample of non-AMA physicians indicate that they have the same total mortality trends as the AMA physicians. Because there was no selection bias the death rate among the physicians was not initially abnormally low. Thus it was not necessary to exclude the first years of follow up from the analyses as was done in the British study. ${ }^{10}$

The AMA physicians comprised $83 \%$ of all male physicians aged 35-64 years and $40 \%$ of all male physicians aged $25-34$ years and $>65$ years. Hence they represented most of the established practising physicians in California. On 1 January 1950 their average age was 48.4 years, and their age distribution was as follows : $11 \cdot 1 \%$ aged $25-34$ years, $36 \cdot 7 \%$ aged $35-44$ years, $24.5 \%$ aged $45-54$ years, $15.2 \%$ aged $55-64$ years, $9 \cdot 2 \%$ aged $65-74$ years, $3 \cdot 0 \%$ aged $75-84$ years, and $0.2 \%$ aged 85-99 years. Four physicians aged 24 years were excluded. Although the race of the physicians still alive was not known, the cohort as a whole may be considered to be essentially white, since non-whites accounted for only $1 \%$ of the deaths. The 1950 US Census of Population showed that California physicians had a median 20 years of education compared with $9 \cdot 3$ years for US white men aged $\geqslant 25$ years and $100 \%$ of the physicians had 16 or more years of education compared with $7 \%$ of US white men aged $\geqslant 25$ years. Physicians had a median income about twice that of employed white men. ${ }^{22}$ Clearly, the socioeconomic state of physicians was far above average during the period of this study.

Based on the data from the numerous surveys in fig 1 , the percentage of California and other US physicians who smoked cigarettes declined from about $53 \%$ in 1950 to about $10 \%$ in 1980 and the percentage of $\omega$ US men who smoked cigarettes declined from $53 \%$ to $38 \%$ over the same period. The ratio of percentage of physician smokers divided by percentage of male smokers declined from about 1.00 in 1950 to about 0.66 in $1960,0.44$ in 1970 , and 0.26 in 1980 . The physician smoker appeared to have smoked about as much (one packet of cigarettes a day) as the typical male smoker, ${ }^{213} 14$ though the most recent survey $\mathrm{N}$ indicates somewhat less. ${ }^{20}$ The tar and nicotine contents of cigarettes smoked by physicians and other men appeared to be similar and the average amounts per cigarette had fallen by over $60 \%$ since 1950 . In addition to the physicians who smoked cigarettes, a further $10-15 \%$ were pipe or cigar smokers. ${ }^{214} 20$ There did not appear to have been major changes in pipe and cigar smoking habits, but the data were incomplete.

Studying physicians for their smoking habits is complicated by the possibility that they may differ from the general population with respect to other factors in life style besides socioeconomic state, and little is known about these other habits. A 1979 study of family

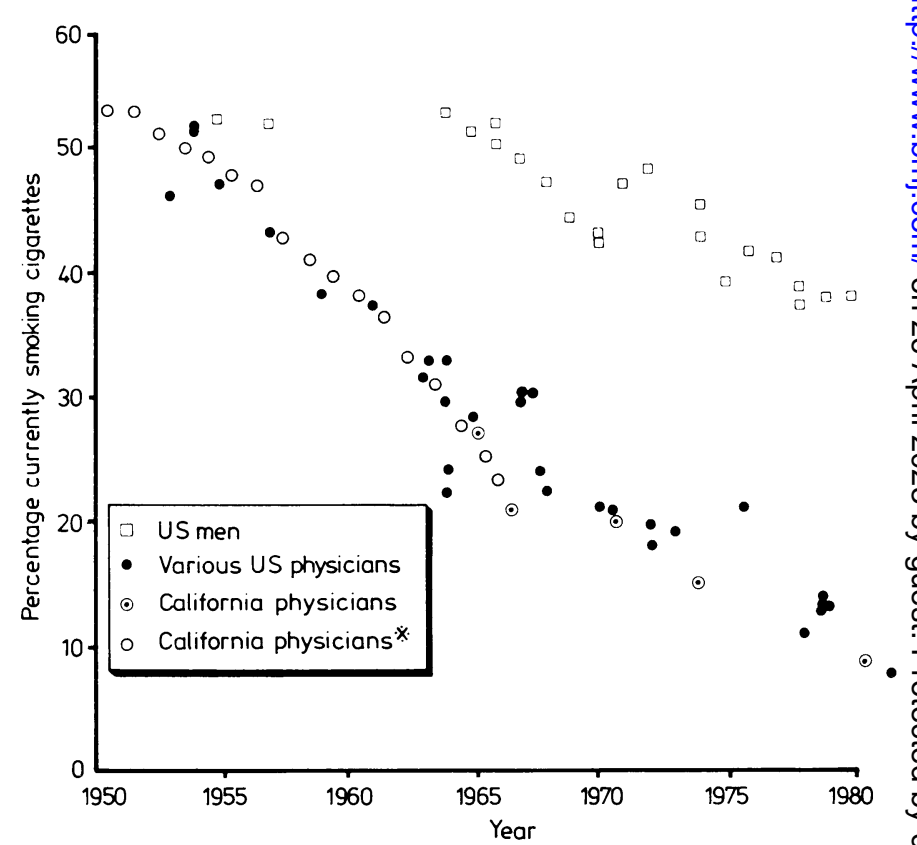

FIG 1-Reported percentages of current cigarette smokers among various samples of US male physicians and US men since 1950.

* Extrapolated from California Medical Association data ${ }^{13}$ and unpublished data of CMA Bureau of Research and Planning ("Study of attitudes and $\supset$ opinions of physicians on smoking," September 1967). 
physicians showed a difference for a few health practices, such as moderate drinking, reduced dietary cholesterol intake, and increased bran intake. ${ }^{17}$ Two recent Massachusetts surveys reported that a substantial portion of physicians practised dietary moderation such as reduced meat and egg consumption and used other preventive measures, such as regular health examinations and seat belts. ${ }^{18}{ }^{20} \mathrm{~A}$ representative survey of Alameda County California adult residents showed that in both 1965 and 1974 physicians and lawyers adhered to an average of 5.6 out of seven health habits compared with an average of 4.9 health habits adhered to by the total population. The seven habits included never smoking cigarettes, moderate drinking, proper weight, proper sleep, exercise, and regular eating patterns and are described in detail elsewhere. ${ }^{14}$ In summary, physicians appeared to have somewhat better health habits than the general population, but there was no available evidence that they had changed habits other than cigarette smoking to any substantial degree since 1950. More data, however, are necessary on this issue.

The mortality analysis first determines person years of observation by attained age in five year intervals and then calculates expected deaths based on contemporaneous death rates among US white men for the six five year periods between 1 January 1950 and 31 December 1979.12 There were 228400 person years of observation. The standardised mortality ratio, or ratio of observed to expected deaths, was determined for the following causes known from previous studies to be most strongly related to smoking: lung cancer; other respiratory, oesophageal, and buccal cavity cancer; bronchitis, emphysema, and asthma; and ischaemic heart disease (called coronary heart disease before 1968). The following "stress related" causes which may be influenced by giving up smoking are included: cirrhosis of the liver, suicide, and all other external causes (accidents, poisonings, and other violence). In addition, cerebrovascular disease, residual circulatory diseases, and residual cancer, along with total mortality were analysed. The standardised mortality ratio for specific causes was artificially increased by the fraction of deaths (about $2 \%$ ) for which cause had not been determined. Table II shows the overall 30 -year standardised mortality ratio and the total number of observed deaths for each disease category. Table III shows the standardised mortality ratios for $1950-9,1960-9$, and $1970-9$ by disease category. Table IV summarises the standardised mortality ratio by five year periods for lung cancer, ischaemic heart disease, and total mortality and describes the regression line that has been fitted by maximum likelihood to the standardised mortality ratios versus time using 30 single year ratios. All tabular results are potentially subject to small errors affecting the observed and expected deaths.

For lung cancer the standardised mortality ratio declined significantly from 62 in 1950-9 to 30 in 1970-9. For ischaemic heart disease the ratio declined even more significantly from 115 in 1950-4 to 69 in 1975-9. The other strongly smoking related causes also declined by a substantial amount. The total death rate declined significantly from 89 in 1950-4 to 67 in 1975-9 and declined for all age groups when analysed either by attained age at death or by initial age in 1950. Most other causes did not show significantly changing patterns in ratio. Most noticeably the standardised mortality ratio of about 200 for suicide was the only one higher than expected.

Interestingly the mortality patterns among all physicians converged toward those for physicians who were non-smokers for the entire 30 years, based on data in tables II, III, and IV for the subgroup of 1180 physicians who graduated from Loma Linda University. These

TABLE II-1950-79 standardised mortality ratio for 10130 California male physicians and 1180 non-smoking California male physicians (Loma Linda University graduates) relative to contemporaneous US white men, and 1966-8 standardised mortality ratio for representative sample of US white men who never smoked cigarettes (24) for selected causes. Figures in parentheses are numbers of deaths on which each standardised mortality ratio is based

\begin{tabular}{|c|c|c|c|c|c|}
\hline \multirow[b]{3}{*}{ Cause of death } & \multirow[b]{3}{*}{ ICD $7^{*}$} & \multirow[b]{3}{*}{ ICD $8^{*}$} & \multicolumn{3}{|c|}{ Standardised mortality ratio } \\
\hline & & & \multicolumn{2}{|c|}{ 1950-79 California male physicians } & \multirow{2}{*}{$\begin{array}{l}1966-8 \text { US white } \\
\text { male never smokers }\end{array}$} \\
\hline & & & Total cohort & Non-smokers & \\
\hline $\begin{array}{l}\text { Lung cancer } \\
\end{array}$ & $162-163$ & 162 & $44(144)$ & $14(5)$ & $22(108)$ \\
\hline $\begin{array}{l}\text { Other respiratory, oesophageal, and buccal } \\
\text { cavity cancer } \\
\text { All other cancer } \\
\text { Ischaemic heart disease } \\
\text { Cerebrovascular disease } \\
\text { All other cardiovascular diseases } \\
\text { Bronchitis, emphysema, and asthma } \\
\text { Cirrhosis of liver } \\
\text { Suicide } \\
\text { All other external causes } \\
\text { All other causes } \\
\text { All causes (only deaths where cause known) } \\
\text { All causes (all deaths included) }\end{array}$ & $\begin{array}{c}140-150,160,161,164,165 \\
151-159,170-205 \\
420 \\
330-334 \\
400-416,421-468 \\
241,501,502,527 \cdot 1 \\
581 \\
\text { E963, E970-979 } \\
\text { E800-962, E980-985 }\end{array}$ & $\begin{array}{c}140-150,160,161,163 \\
151-159,170-209 \\
410-414 \\
430-438 \\
390-404,420-429,440-458 \\
490-493 \\
571 \\
\text { E950-959 } \\
\text { E800-949, E960-999 }\end{array}$ & $\begin{array}{l}61(54) \\
85(664) \\
83(2135) \\
83(544) \\
70(507) \\
44(65) \\
62(63) \\
201(158) \\
74(182) \\
52(477) \\
75(4993) \\
75(5090)\end{array}$ & $\begin{array}{l}23(2) \\
71(52) \\
61(145) \\
69(34) \\
45(24) \\
20(3) \\
34(4) \\
178(16) \\
113(30) \\
74(38) \\
59(353) \\
59(375)\end{array}$ & $\begin{array}{l}62(100) \\
86(462) \\
80(559) \\
93(157) \\
80(235) \\
31(135) \\
76(37) \\
95(36) \\
90(114) \\
72(589) \\
77(2532) \\
77(2532)\end{array}$ \\
\hline
\end{tabular}

* International Classification of Diseases: $\mathrm{ICD} 7=7$ th revision, $\mathrm{ICD} 8=8$ th revision.

TABLE III-Standardised mortality ratio (SMR) for 10130 California male physicians and 1180 non-smoking California male physicians by decade of follow up for selected causes

\begin{tabular}{|c|c|c|c|c|c|c|c|c|c|}
\hline \multirow[b]{3}{*}{ Cause of death } & \multicolumn{9}{|c|}{ Standardised mortality ratio* } \\
\hline & \multicolumn{2}{|c|}{$1950-9$} & \multicolumn{2}{|c|}{$1960-9$} & \multicolumn{5}{|c|}{$1970-9$} \\
\hline & SMR & Obs & SMR & Obs & SMR & Obs & $\operatorname{Exp}_{1}$ & $\operatorname{Exp}_{2}$ & Obs-Exp ${ }_{2}$ \\
\hline \multicolumn{10}{|c|}{ All physicians } \\
\hline $\begin{array}{l}\text { Lung cancer } \\
\text { Other respiratory, oesophageal, and buccal }\end{array}$ & 62 & 34 & 54 & 59 & 30 & 51 & 170 & 106 & $-55+$ \\
\hline $\begin{array}{l}\text { Other respiratory, oesophageal, and buccal } \\
\text { cavity cancer }\end{array}$ & 100 & 23 & 29 & 9 & 63 & 22 & 35 & 35 & -13 \\
\hline All other cancer & 92 & 187 & 83 & 215 & 80 & 262 & 326 & 301 & $\begin{array}{l}-39 \\
-39\end{array}$ \\
\hline Ischaemic heart disease & 106 & 635 & 83 & 752 & 71 & 748 & 1050 & 1108 & $-360+$ \\
\hline Cerebrovascular disease & 82 & 144 & 94 & 211 & 76 & $\begin{array}{l}180 \\
189\end{array}$ & 249 & 204 & $\begin{array}{l}-3001 \\
-15\end{array}$ \\
\hline All other cardiovascular diseases & 68 & 172 & 83 & 214 & 57 & 121 & 211 & 143 & -22 \\
\hline Bronchitis, emphysema, and asthma & 62 & 16 & 46 & 26 & 35 & 23 & 67 & 41 & $-18 \ddagger$ \\
\hline Cirrhosis of the liver & 67 & 19 & 59 & 22 & 60 & 22 & 36 & 24 & $-2+$ \\
\hline Suicide & 182 & 54 & 225 & 63 & 195 & 41 & 21 & 38 & +3 \\
\hline All other external causes & 62 & 57 & 80 & 68 & 80 & 57 & 71 & 45 & +12 \\
\hline All other causes & 46 & 112 & 53 & 164 & 55 & 201 & 364 & 163 & $+38 t$ \\
\hline All causes (only deaths where cause known) & 84 & 1453 & 78 & 1803 & 67 & 1737 & 2600 & 2208 & $-471+$ \\
\hline All cáuses (all deaths included) $\S$ & 84 & 1503 & 78 & 1830 & 67 & 1757 & 2630 & & \\
\hline \multicolumn{10}{|c|}{ Non-smoking physicians } \\
\hline All causes (all deaths included) $\S$ & 62 & 70 & 61 & 133 & 56 & 172 & & & \\
\hline
\end{tabular}

* Obs $=$ Observed deaths. Exp $_{1}=$ Expected deaths based on 1970-9 US white male death rates. Exp $_{2}=$ Exp $_{1}$ times $1950-9$ SMR. Obs-Exp $2=$ Net change in deaths due to SMR changes in physicians.

Includes deaths for which cause not yet determined, and SMR for each specific cause increased by fractior that unknown deaths are of total deaths.

$\dagger \mathrm{p}<0.001$ and $\neq \mathrm{p}<0.01$ indicate that $\mathrm{Obs}$ is different from $\mathrm{Exp}_{2}$ at significance level of $\mathrm{p}$ based on two tailed test for ratio of observed value of Poisson variable to its expectation. 
TABLE IV-Detailed standardised mortality ratio trends for lung cancer, ischaemic heart disease, and all causes by five year periods of follow up. Slope, standard error $(S E)$, and statistical significance $(p)$ of linear regression of standardised mortality ratio versus time using single year data

\begin{tabular}{|c|c|c|c|c|c|c|c|c|c|}
\hline \multirow[b]{2}{*}{ Cause of death } & \multicolumn{6}{|c|}{ Standardised mortality ratio by five year periods } & \multicolumn{3}{|c|}{ Yearly change in standardised mortality ratio } \\
\hline & $1950-4$ & $1955-9$ & $1960-4$ & $1965-9$ & $1970-4$ & $1975-9$ & Slope & $\mathrm{SE}$ & $\mathrm{p}$ \\
\hline \multicolumn{10}{|c|}{ All physicians } \\
\hline $\begin{array}{l}\text { Lung cancer }(\geqslant 25 \text { years) } \\
\text { Ischaemic heart disease ( } \geqslant 25 \text { years) } \\
\text { All causes (all deaths included): }\end{array}$ & $\begin{array}{r}51 \\
115\end{array}$ & $\begin{array}{l}70 \\
97\end{array}$ & $\begin{array}{l}52 \\
86\end{array}$ & $\begin{array}{l}57 \\
80\end{array}$ & $\begin{array}{l}29 \\
74\end{array}$ & $\begin{array}{l}30 \\
69\end{array}$ & $\begin{array}{l}-1 \cdot 0 \\
-1.8\end{array}$ & $\begin{array}{l}0.5 \\
0.2\end{array}$ & $\begin{array}{ll} & 0.05 \\
< & 0.0001\end{array}$ \\
\hline $\begin{array}{l}25-64 \text { years }(1950 \text { age) } \\
25-64 \text { (attained age) } \\
65-84 \text { (attained age) } \\
25-84 \text { (attained agc) } \\
\geqslant 25 \text { years }\end{array}$ & $\begin{array}{l}86 \\
86 \\
92 \\
89 \\
89\end{array}$ & $\begin{array}{l}74 \\
69 \\
88 \\
79 \\
80\end{array}$ & $\begin{array}{l}80 \\
82 \\
81 \\
81 \\
79\end{array}$ & $\begin{array}{l}76 \\
70 \\
78 \\
75 \\
78\end{array}$ & $\begin{array}{l}66 \\
57 \\
69 \\
66 \\
67\end{array}$ & $\begin{array}{l}66 \\
58 \\
66 \\
65 \\
67\end{array}$ & $\begin{array}{l}-0 \cdot 8 \\
-1 \cdot 1 \\
-1 \cdot 0 \\
-1 \cdot 0 \\
-0.9\end{array}$ & $\begin{array}{l}0 \cdot 2 \\
0 \cdot 2 \\
0 \cdot 2 \\
0 \cdot 2 \\
0 \cdot 2\end{array}$ & $\begin{array}{l}<0.0001 \\
<0.0001 \\
<0.0001 \\
<0.0001 \\
<0.0001\end{array}$ \\
\hline \multicolumn{10}{|c|}{ Non-smoking physicians } \\
\hline $\begin{array}{l}\text { All causes (all deaths included): } \\
\geqslant 25 \text { years }\end{array}$ & 59 & 64 & 64 & 59 & 57 & 54 & $-0 \cdot 2$ & 0.2 & $>0.05$ \\
\hline
\end{tabular}

graduates have previously been shown to be essentially all nonsmoking Seventh-Day Adventists, ${ }^{23}$ and our standardised mortality ratios are in good agreement with the published ones. The overall ratio declined from 84 during $1950-9$ to 67 during 1970-9 for all physicians, but only from 62 to 56 for graduates of Loma Linda University. This suggests that the relative decline in mortality from lung cancer and ischaemic heart disease among California physicians was in large part related to their giving up smoking. This is further confirmed by the fact that during 1970-9 physicians (table III) had standardised mortality ratios for the strongly smoking related causes that were very similar to those of representative 1966-8 US white men who never smoked cigarettes, ${ }^{24}$ but not as low as those for the nonsmoking physicians as shown in table II. As noted above, it appears that physicians had somewhat better health practices than the general public, but it is not clear that these habits had changed like their smoking habits. ${ }^{1-20}$ These other habits may have influenced their overall mortality trends, particularly ischaemic heart disease, but they are not likely to have had a substantial impact on their trends in lung cancer mortality.

In order further to analyse the nature of the mortality changes among the physicians, an exercise was done similar to that by Lee for British physicians. ${ }^{25}$ For each specific cause in table III the expected deaths during 1970-9 based on death rates among US white men $\left(\operatorname{Exp}_{1}\right)$ are multiplied by the $1950-9$ standardised mortality ratio in order to determine the number of expected deaths had the ratio remained as it was in the $1950-9\left(\operatorname{Exp}_{2}\right)$. Comparison with the 1970-9 observed deaths gives the number of lives "saved" or "lost" if there had been no change in ratio since 1950-9. The net savings of 471 deaths was $21 \%$ of the total expected deaths. The savings among the primary smoking related causes were distributed as follows: 55 from lung cancer, 13 from other smoking related cancers, 18 from bronchitis, emphysema, and asthma, and 360 from ischaemic heart disease for a total of 446 deaths. There was a loss of 13 stress related deaths from cirrhosis of the liver, suicide, and all other external causes and a saving of 38 deaths from all remaining causes. Thus $95 \%(446 / 471)$ of the net savings occurred among the primary smoking related causes of death, lending further support to the notion that the relative improvement in the health of physicians was due in large part to their giving up smoking.

\section{Discussion}

It is useful to compare the 10130 California male physicians with the 34440 British male physicians who were followed up by Doll and Peto from 1951 to $1971 .^{10}$ There was a significant relative decline in both cigarette smoking and mortality from lung cancer among the British physicians compared with other British men. The relative decline in lung cancer from about $65 \%$ to $35 \%$ occurred within 20 years among British physicians, whereas it took more than 20 years to fall from $62 \%$ to $30 \%$ among California physicians. Only those British physicians with attained age less than 65 years showed any relative improvement in total mortality, whereas the California physicians of all ages showed improvement. It is also important that the relative decline in lung cancer occurred because the absolute death rate among California physicians remained roughly constant while more than doubling in the general population. This point is

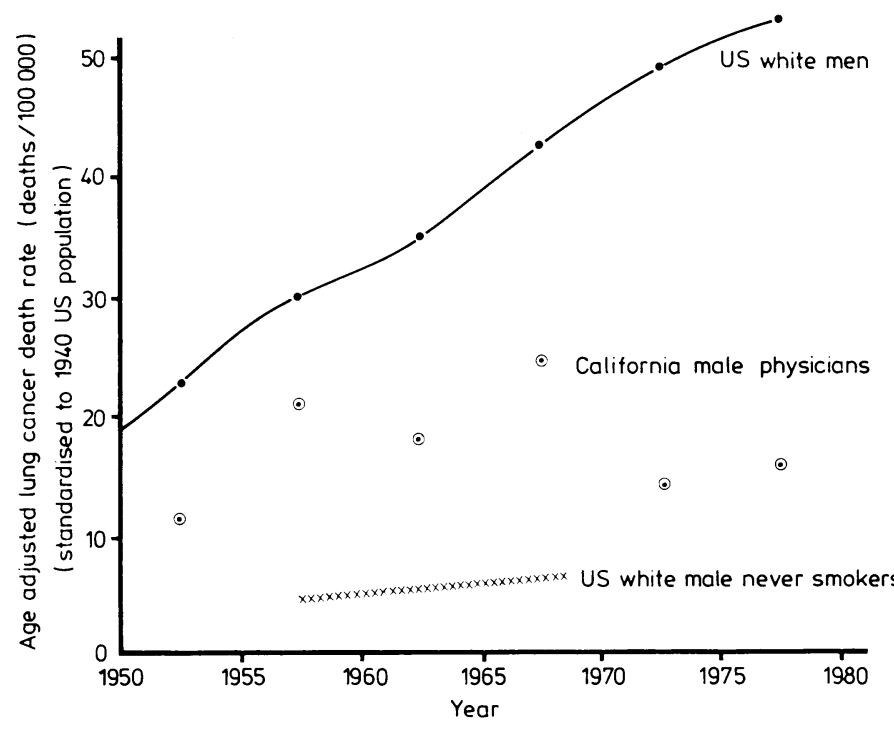

FIG 2-Yearly age adjusted lung cancer death rate, standardised to 1940 US population, for US white men and California male physicians. Physician rate estimated using standardised mortality ratios in table IV, and rate for never smokers estimated from published data. ${ }^{1-4} 24$

illustrated in fig 2 by applying the physician standardised mortality ratios to the age adjusted US white male lung cancer death rate.

The most important absolute and relative declines in mortality were in total mortality, particularly that from ischaemic heart disease, and the declines became most pronounced after more than 20 years of follow up. These declines occurred to differing extents among both physicians and the general population and were largely responsible for increasing the life expectancy from age 25 since 1950 by about five years for California physicians compared with about three years for US white men. In order to provide additional evidence that this decline in total mortality was genuine, a comparison is made with published data on US physicians. Goodman showed that the overall standardised mortality ratio for all US male physicians relative to US white men declined from about 93 in 1949-51 to 75 in 1969-74 based on AMA cross sectional mortality data. ${ }^{26}$ Since the ratio had remained relatively constant with values of 91 in 1925 and 102 in 1938-42, the 1969-73 data represent the first major decline. Also, Goodman showed that physicians aged 50 years and above in the Pacific census division, $75 \%$ of whom lived in California, had a 1969-73 standardised mortality ratio of 67 , which was the same as the 1970-4 ratio among California physicians aged about 50 years and above. In summary, the standardised mortality ratio declined about the same relative amount in both California and US physicians, but the absolute ratios were somewhat lower among California physicians during each period. Also the distribution of deaths among 
physicians in this cohort was in good agreement with the distribution found in a recent analysis of all deaths among California physicians during 1959-61. ${ }^{27}$

Advantages of this study design include the following: the cohort was not subject to a questionnaire respondent effect: the population as a whole had essentially stopped smoking but had remained essentially unchanged occupationally and socioeconomically; follow up over 30 years was close to $100 \%$ complete and accurate: and an assessment was possible of the impact of stopping smoking on overall mortality, as well as specific smoking-related causes, among the cohort as a whole. Disadvantages include the following: actual smoking histories were not obtained for California physicians until 1965 and were based on several non-random samples, though the consistency of the various smoking data and the very large changes over time tended to confirm the validity of our assumption about their smoking patterns; data on other health habits and possible changes in these habits were very limited and might have affected some of the findings; and cause specific time trends had the weakness that relatively few deaths among physicians and the general population were confirmed by necropsy-for instance, the proportion of deaths among physicians that had a postmortem examination was only about $40 \%$ in 1950 and declined to about $20 \%$ in 1979.

Clearly this study was not a rigorous randomised controlled trial. But it included a large cohort with a major change in smoking habits relative to the compared population, covered a 30 year follow up period, and had enough statistical power to detect a relative decline in lung cancer by decade. The smaller change in smoking habits, the shorter follow up period, and much smaller number of total deaths may explain the insignificant differences in total mortality observed in three recent randomised controlled trials. ${ }^{7 \cdots 9}$ That total mortality showed such a large relative decline among physicians means that they had experienced a large overall improvement in their health irrespective of potential errors in the assignment of underlying cause of death. While it is not possible absolutely to rule out alternative explanations, the most plausible explanation of this study is that giving up smoking by California physicians has substantially decreased their relative but not absolute death rate from lung cancer and contributed substantially to their reduced relative and absolute total death rate as well. The interpretation with respect to total mortality, however, is critically dependent on the reason for the decline in ischaemic heart disease, which may be largely due to factors other than stopping smoking. This issue cannot be resolved with the present study design and additional detailed data are needed on the California physicians. What can be concluded with certainty is that California male physicians have essentially all stopped smoking and that their death rate from smoking related diseases has declined significantly relative to the general male population over 30 years.

This research has been supported by grant CA 23974 and Preventive Oncology Academic Award CA 00748 from the National Cancer Institute. The American Medical Association provided information on deceased California physicians. California Department of Health Services provided death certificate information on all California deaths. Linda E Kanin, Richard J Biermann, Betty M Isbell, Shiva Ristani, Saboohi A Currim, Samuel J Tobin, and Dr Roger E Bolus provided technical help.

\section{References}

1 Advisory Committee to the Surgeon General of the Public Health Service. Smoking and health. Washington, DC: US Government Printing Office, 1964. (Public Health Service publication No 1103.)

2 Surgeon General. Smoking and health. Washington, DC: US Government Printing Office, 1979: ch 22 and Appendix. (Public Health Service publication No 79-50066.)

${ }^{3}$ Surgeon General. The health consequences of smoking: cancer. Washington DC: US Government Printing Office, 1982. (DHSS (PHS) publication No 82-50179.)
4 Doll R, Peto R. The causes of cancer: quantitative estimates of avoidable risks of cancer in the United States today. $\mathcal{F N C I} 1981 ; 66: 1191-308$.

${ }^{5}$ Fisher RA. Smoking: the cancer controversy. Some attempts to assess the evidence. Edinburgh: Oliver and Boyd, 1959.

${ }^{6}$ Burch PRJ. The biology of cancer: a new approach. Baltimore: University Park Press, 1976.

${ }^{7}$ Rose G, Hamilton PJS, Colwell L, Shipley MJ. A randomised controlled trial of antismoking advice: ten-year results. $\mathcal{F}$ Epidemiol Community Health $1982 ; 36: 102-8$.

${ }^{8}$ Hjermann I, VelveByre K, Holme I, Leren P. Effect of diet and smoking intervention on the incidence of coronary heart disease. Lancet 1981 ;ii : 1303-10.

${ }^{9}$ MRFIT Research Group. Multiple risk factor intervention trials: risk factor changes and mortality results. FAMA 1982;248:1465-77.

10 Doll R, Peto R. Mortality in relation to smoking: 20 years' observations on male British doctors. Br Med F 1976;ii:1525-36.

${ }^{11}$ American Medical Association. American medical directory. 18-27th eds. Chicago, Ill: AMA, 1950-79.

12 Monson RR. Analysis of relative survival and proportional mortality. Comput Biomed Res 1974;7:325-32.

13 California Medical Association. The smoking study: a report of the attitudes and habits of California physicians with respect to cigarette smoking. California Medicine 1968;109:339-44.

14 Breslow L, Enstron JE. Persistence of health habits and their relationship to mortality. Prev Med 1980;9:469-83.

${ }^{15}$ Lipp MR, Benson SG. Physician use of marijuana, alcohol and tobacco. Am $\mathcal{F}$ Psychiatry 1972;129:612-6.

${ }^{16}$ Lewis R. Doctors quit smoking, but can't convince patients. World Smoking Health 1982; 7:30-1.

17 American Academy of Family Physicians. Lifestyles/personal health care in different occupations: a study of attitudes and practices. Kansas City, Mo: AAFP, 1979.

${ }_{18}$ Wyshak G, Lamb GA, Lawrence RS, Curran WJ. A profile of the healthpromoting behaviors of physicians and lawyers. N EnglF Med 1980;303: 104-7.

19 American Cancer Society. The impact of providing physicians with quit-smoking materials for smoking patients. $C A$ 1981;31:75-8.

20 Johnson GT, ed. Personal health practices-how do you compare to the Harvard Medical School faculty? The Harvard Medical School Health Letter 1982;VII :1-6.

${ }^{21}$ Burgess AM, Tierney JT. Bias due to non-response in a mail survey of Rhode Island physicians' smoking habits-1968. N Engl f Med 1968; 282:908.

${ }^{22}$ US Bureau of the Census. US census of population, 1950. Washington, DC: US Government Printing Office, 1953.

${ }^{23}$ Phillips RL. Role of lifestyle and dietary habits in risk of cancer among Seventh-Day Adventists. Cancer Res 1975;35:3513-22.

${ }^{24}$ Enstrom JE, Godley FH. Cancer mortality among a representative sample of nonsmokers in the United States during 1966-68. FNCI 1980;65: 1175-83.

${ }^{25}$ Lee PN. Has the mortality of male doctors improved with the reduction in their cigarette smoking ? Br Med f 1979;ii:1538-40.

${ }^{26}$ Goodman LJ. The longevity and mortality of American physicians, 1969-1973. Milbank Mem Fund $Q$ 1975;53:353-75.

27 National Institute of Occupational Safety and Health. Occupational mortality in the State of California. 1959-1961, Cincinnati, Ohio: NIOSH, 1980. (DHEW(NIOSH) publication No 80-104.)

(Accepted 9 December 1982)

CLEANSING MEDICINES-Cleansing medicines can neither be defined by heat, nor coldness, because some of both sorts cleanse. A cleansing medicine, then, is of a terrene quality, which takes away the filth with it, and carries it out. Here, to avoid confusion, a difference must be made between washing and cleansing. A thing which washeth, carries away by fluxion, as a man washeth the dirt off from a thing. A cleansing medicine by a certain roughness or nitrous quality, carries away the compacted filth with it. This also is the difference between cleansing and discussing medicines, the one makes thick humours thin, and so scatters them, but a cleansing medicine takes the most tenacious humour along with it, without any alteration. Besides, of cleansing medicines, some are of a gentler nature, some are more vehement. These are not known one and the same way; for some are sweet, some salt, and some bitter. The use of cleansing is external, as the use of purges are internal. They are used to cleanse the sanies and other filth of ulcers, yea, and to consume and eat away the flesh itself, as burnt Alum, precipitate, \&c. When these must be used, not only the effects of the ulcers, but also the temperature of the body will tell you. For if you see either a disease of fulness, which our physicians call [Plethora] or corrupted humours which they call [Cacochyma] you must empty the body of these, viz fulness by bleeding, and corrupt humours, or evil state of the body, by purging before you use cleansing medicines to the ulcer, else your cure will never proceed prosperously. (Nicholas Culpeper (1616-54) The Complete Herbal, 1850.) 